\title{
4.2
}

\section{Methodological Approaches to Reflect on the Relationships Between People, Spaces, Technologies}

\author{
Barbora Čakovská $^{1(\bowtie)}$, Mária Bihuňová ${ }^{1}$, Preben Hansen ${ }^{2}$, \\ Ernesto Marcheggiani ${ }^{3,4}$, and Andrea Galli ${ }^{3}$ \\ ${ }^{1}$ Horticulture and Landscape Engineering Faculty, \\ Slovak University of Agriculture, Nitra, Slovakia \\ barboralipovska@gmail.com, bihunova.maria@gmail.com \\ ${ }^{2}$ Department of Computer and Systems Sciences, Stockholm University, \\ Stockholm, Sweden \\ preben@dsv.su.se \\ 3 Department of Agricultural, Food and Environmental Sciences, \\ Università Politecnica delle Marche, Ancona, Italy \\ \{e.marcheggiani,a.galli\}@univpm.it \\ ${ }^{4}$ Department of Forest, Nature and Landscapes, KU Leuven, Leuven, Belgium
}

\begin{abstract}
Social behaviour in public spaces has changed over the time and has become attractive to all those involved in designing people's spaces. Communities in different countries in Europe have shown more and more interest and various activities have started to shape the public spaces all round the world. The main objective of the chapter is to review development of the methodologies that have been used to analyse public spaces worldwide and to summarize their requirements and conditions to suggest how they can be applied in order to analyse the relationship between people and spaces, with the aim to boost the active participation of people in design process. The chapter describes the methodologies using ICTs, especially e-participation, mobile technologies, GIS systems, or on the methodologies increasing the attractiveness of the public open spaces for citizens and visitors (laser holograms, QR codes, interactive boards, online and interactive maps, questionnaires and social interaction, etc.). Information technology offers new potentials of citizen participation and provides a communication platform, which suppresses a barrier of nonprofessionalism, allowing for distant contacts and enabling participatory process management. Users, accustomed to communicating through ICT also in public spaces, feel by using this tool more anonymous and less harassed to express their opinion. Not only ICT are important in the 21 st century society, but also new ways of social media, which are accessible/open to use for larger group of people. The institutions or municipalities could use them as semiofficial information platform, public open discuss forums or resource of the public initiatives.
\end{abstract}

Keywords: Blended spaces - Public space users - E-participation · Playful tools $\cdot$ Top-down initiatives $\cdot$ Urban planning 


\section{Introduction}

Carr et al. (1992) regard public space as "the common ground where people carry out the functional activities that bind a community, whether in the normal routines of daily life or in periodic festivities". It is the stage upon which the drama of communal life unfolds." For Madanipour (1996) public space is a space we share with strangers, people who aren't our relatives, friends, or work associates. It is space for politics, religion, commerce, sport; space for peaceful coexistence and impersonal encounter. Users are described by Lynch (1984) as all those who interact with the place in any way: live in it, work in it, pass through it, repair it, control it, profit from it, suffer from it, even dream about it.

Space and society are clearly related: it is difficult to conceive of 'space' without social content and, equally, to conceive of society without a spatial component. The relationship is best conceived as a continuous two-way process in which people (and societies) create and modify spaces while at the same time being influenced by them in various ways (Carmona 2003).

People's behaviour in public spaces has become attractive not only for psychologists, sociologists, interaction design or urban geographers but also for urban planners, architects, landscape architects and all those involved in designing people's spaces (Carr et al. 1992; Carmona 2003; Gehl 2011). Social behaviour in public spaces has changed over the time. Communities in different countries in Europe have shown more and more interest in these public spaces and various activities have started to shape these public spaces, or even the landscape where people live. Due to this development a new discipline of environmental participatory design emerged, devoted to researching how built environments work for people and how people affect the public space with their activities (Wheeler 2004).

\section{People-Space Methods}

The way the urban environment is designed and provides access to the natural environment and different types of activities reflects the current priorities of the society and its level of awareness. The assessments of the urban open spaces have been studied by scientist, architects, planners and sociologists. Several urban design guidelines have been published with the aim to respect the place, its functions, demands of the citizens, improving the quality of the life and environment, support the social contacts or include the minorities to the society and motivate and change social behaviour towards healthy living (Miková et al. 2010; Melková 2014).

It is well known as pollution affects human health and living organisms in general. Nevertheless, recent findings highlight that also the spatial topology and landscape arrangements - not limited to pollution - can lead to structural and functional human disorders. In particular, how brain neurotransmitters and limbic (emotional) systems changes during our life (Vanderhaeghen et al. 2010) as to register environmental inputs is being looked at by new branches of landscape ecology and neuroscience. First results of the so-called landscape Bionomy (Ingegnoli 2015) shows how a redundancy of neuronal connections during infancy is afterwards soon pruned around the age of 5 . 
This suggests that the environment in which man has to live form the wider part of the input modelling the brain concerns landscape conditions. It is inevitable that landscape structural alterations, could lead to human hilliness, even in absence of pollution. For the physical environment supports human behaviour, the bulk of human-space relationships are of extreme importance.

Researchers developed methods using behaviour observation, time-lapse photography, post-occupancy evaluation surveys, and cognitive mapping (in which people were asked to draw maps or images of how they perceived their urban environments) to provide factual information for improved urban design (Wheeler 2004). Cognitive mapping could be presented as mental maps or parish maps (in which people were asked to draw maps or images of how they perceived their urban environments as well as the open spaces (landscape in a wide sense) to provide factual information for improving the urban design. This method also enables local people and tourists to deeper discover the meaning of places while they enjoy all their attractiveness.

Beginning in the 1960s writers such as Jacobs, Lynch, William H. Whyte, Clare Cooper Marcus and Danish designer Jan Gehl emphasised the need to base urban design on study of how people actually experience and use urban environments. The American urbanist, organizational analyst, journalist and people-watcher William $\mathrm{H}$. Whyte studied human behaviour in urban settings. He observed, and film analysed plazas, urban streets, parks and other open spaces in New York City. All told, Whyte walked the city streets for more than 16 years. As unobtrusively as possible, he watched people and used time-lapse photography to chart the meanderings of pedestrians. What emerged through his intuitive analysis is an extremely human, often amusing view of what is staggeringly obvious about people's behaviour in public spaces, but seemingly invisible to the inobservant (PPS 1999).

In 1980s Randolph Hester was a leader of planning process in Manteo town (North Carolina, USA). In this process residents identified what they valued about life and about their landscape. Hester comments that these important social patterns and places came to be called the „Sacred Structure "by locals and inspired a plan for community revitalization and development that was controlled by them. Planning focused on behaviour mapping that recorded what people did and where they did it - things that were not revealed in the standard surveys. Activities like the exchange of small talk at the post office, hanging out at the docks, checking out the water for the tides, the fishing, and the weather, happened in the same places every day. Daily rituals indicated a dependence on specific places that could be disrupted by changes in land use. A list of these was developed, and people were asked to rank them in order of their significance, and to indicate which ones could be sacrificed in the interest of tourist facilities. From these was published a map of places that people wanted protected from future development (Hough 1990).

Francis (1984) has presented in his method of downtown and neighbourhood planning the importance of traffic mapping, parking problems and pedestrian flow mapping. Activity mapping as a useful information for planning process was proved by Francis (1984), when he used the activity mapping in Davis town. Based on the activity analyses the design solution was made. The study and research of Danish architect Jan Gehl is worldwide known. In a book Life Between Buildings (2011) he has specified and described outdoor activities in public spaces into three categories, with special 
needs different demands on the design of the place. There are pointed activities: necessary, optional and social.

Necessary activities are activities appeared almost every day, not depended on the weather conditions or willingness of the participants. These are activities as going to work, shopping, waiting for someone, standing on the bus stop.

Optional activities represent voluntary activities, depended on the will of participants, good weather conditions and the suitable design of the outdoor open space. For example, playing games, meeting friends, doing sports or just sitting on the bench and relaxing.

Social activities include active or passive social interaction. They can be seen between all age groups, between friends or people met randomly. Participants do not need to talk necessary, they could just watch or just listen to.

On the method of direct observation and comparison of results from studies that have been made in the urban environment, we can conclude that people in rural areas use public spaces, like in cities (Lipovská and Štěpánková 2013). Although most of these methods could be done in an unobtrusive way, there are time-consuming aspects, which the professionals might consider as inefficient and out-dated. The research published by Nassar (2015) in Egypt prove that is very important to understand human behaviour together with the social aspects of the local community in an urban space to create a design that increases residents' physical activity. He mentions that there is no perfect solution for the space: the goal is simply to create many opportunities by means of landscape features that allow residents to perform different types of physical activity (for different age groups).

Interesting phenomenon in Germany has been described by Schöbel (2006). While during the 20th century, open space planning was based mainly on quantitative arguments, the current change of attitudes and ideas in society has led to a discussion of 'quality of the open spaces instead of quantity'. Contemporary society is experiencing an economic change from an affluent and industrial society to a worldwide servicebased society. Analyses of the spatial reality of urban society and urban space indicate that this change is being accompanied and increased by spatial polarisation within cities, which in the end affects the population's social chances. Different cultures and social backgrounds, which meet in the cities create challenges and those must be overcome in urban meta-cultures. Great examples are the Pallas-Park in Berlin's neighbourhood Schöneberg and the Park Spoor Noord in Antwerp's Seefhoek district, when the city councils decided to create urban parks, where the different cultures could meet each other. In England there are many state programmes that support the local communities and interaction with neighbourhood via community gardens and garden education. In the Northern countries (Norway, Sweden) the social policy and state support the residential equipment and qualitative design of open spaces with possibilities to play, practise sports, meet and interact with others. Schöbel (2006) has summarised five planning categories characterising the functions and qualities of the entire structure of urban green and open spaces according to the research done in Berlin. It could be applied in any other city.

The analysis of flows - such as human movements - can help spatial planners better understand territorial patterns in urban environments (Chua 2014; 2016). Nowadays 
interactive visual interfaces are designed to gather, extract and analyse human flows in geolocated social media data. Such a system adopts a graph-based approach to infer movement pathways from spatial point type data and expresses the resulting information through multiple linked multiple visualisations to support data exploration.

\section{People-Space-Technology Methods}

The World Economic Forum (2015) published the Top 10 Urban Innovations, which reflect the digital revolution and the best way to improve a city due to increasing number of population and more people living in urban than rural areas. The most interesting are:

1. Re-programming the space - Cities have started to look at reprogramming their space to get more from less: reduced its allowable urban footprint; changing the strategy of expansion to concentration; repurposing asphalt to expand footpaths and open space).

2. Waternet: An Internet of Pipes - Smart water management models use sensors in network pipes to monitor flows and manage the entire water cycle, providing sustainable water for human and ecological needs.

3. Adopt a Tree through Your Social Network - In a database trees could be named, its growth tracked and carbon offset, and data shared through social networks. Each tree could have its own email address which allows citizens to report problems and diseases and even send love letters.

4. Augmented Humans: The Next Generation of Mobility - Improved safety for pedestrians and non-motorized transportation leads to greater adoption of public transport, reduced congestion and pollution, better health and commutes that are quicker. Such relatively low-cost solutions include separate bike lanes, bike-sharing schemes, re-phasing traffic lights to fit the speed of bikes and planting trees along the side of roads to slow traffic.

\section{How the ICTs Could Influence Public Open Spaces}

Online interactive community mapping is the process by which individuals jointly create a community map using modern information and communication technologies (ICT). Such mapping is mostly done to identify the needs and concerns of a community living or brazen in a certain location.

Online interactive mapping is successful if at least some of the following conditions are fulfilled, ideally all. The local community is cardinal, because they are source of local experience and knowledge, they know best what they lack and what would contribute to a better quality of their lives. Second condition is ICT and sufficient eskills. The local community must have sufficient motivation to participate in mapping. The entire process must have a coordinator and facilitator, best representative of the non-profit sector, scientific community or engaging civilian public. It is very important to collect the information only regarding to the aim of mapping. The final community 
map is created by locals and is great base for local authorities to solve problems and improve the quality of life.

Žufová (2015) presents on the example of Bratislava City when the citizens could participate at collection of information, pointing at the problems, control the environment. An interactive website for the citizens was established at www. odkazprestarostu.sk, with the mobile applications TrashOut and Park4disabled. Another possibility concerns the implementation of common ICT, e. g app's tools, to share the local knowledge and stories collected through the participatory process among all citizens that takes place when folk museums (or eco-museums) are in a building phase by a participative process involving a community. Actually, online ICT solutions, usually pieces of software broadcasted to public through the Web called applications or "apps" (Castells 2006; Lugano 2008) are easy to use and very popular. This is a very important prerequisite to the ultimate designing of a sound ICT tools, because a participative approach, traditionally build upon the delivering of a so called "parish maps", simply means "... a dynamic way by which communities preserve, interpret, and manage their heritage for a sustainable development" (Chart of Catania 2007). A key issue for this kind of projects is how to funnel considerable streams of information across and towards the local communities. Considering the widening on the Web mass communication media (GSM, smartphones, tablets, ...), the idea of developing an ICT tools, tailored upon specific characteristics of a given public space or landscape, could represent a useful tool to design and manage these places taking in account all faces of sustainability (economic, ecological, social and cultural).

Nowadays, ICTs are part of everyday life and we still do not use their full potential. This potential could be understood in positive or negative usage. To create the New Social Place of the era of digitalisation, spaces must follow the concept of "human information interaction", which is a concept based on the relation between human, space, and information technologies. Aziz, et al. (2016) define four elements of ICT: Wi-Fi networks, digital interactive media façades, interactive public displays, and smartphones' applications in public spaces. These elements play major roles in the public space in terms of culture and art; education; planning and design; games and entertainment and information and communication. Clever use of ICTs helps to increase the attractiveness of the space, the interaction between people as well as between people and the space around them, which will foster the sense of place and the sense of belonging to the space.

To this purpose, the design of the logical model of an app/tool is the first and very crucial point to deal with. Referring to an experience led in Italy, Galli et al. (2014) were inspired at the contents of the "Parish Map of Montacuto, Paggese and other Acquasanta's villages" (Ascoli Piceno, Italy). The design of this mobile app aimed to provide "virtual scenarios" that reproduce, for example, thematic itineraries around characteristic areas represented in the "parish maps" with the aim to show the point of view (cultural, environmental, social) coming from communities living there. The app, to be used on mobile devices such as GSM, smartphones and tablets, has been engineered in order to offer thematic itineraries discovering the authentic local identity and sense of place. The routes are articulated in "role itineraries", each of them makes visitors to feel as visit-actors, playing roles as if they were a member of the local community, which are based on typical "local characters" of daily working activities in 
that territorial context. The "virtual scenarios" consist mainly of a map of the area, from which, some itineraries can be chosen by clicking on the icons representative of the of available "local characters". Moreover, users can upload and share new original contents, which the app makes visible to all the other members connected through social networks. In this way the "virtual scenarios" can be updated any time users upload new contents, bringing a continuous evolution to scenarios and a higher degree of vitality into social community. In few words, the app orients and encourages both local people and tourists to keep interactively a specific Parish Map alive. A similar approach could be effectively applied to tailor each app tool on the main characteristics of every public space, if the fundamental help of local people were actively favoured (Galli et al. 2015).

A key issue remains the development of innovative ways to manage the most remarkable comments coming from the users (insiders and outsiders) of the app; and how to foster the participation of administrators and land managers, in order to refuel the debate on the sustainable development of public spaces. Hampton (2014) compared the time-lapse photography of both William Holly Whyte and PPS to analyse human behaviour in the public space of Bryant Park in the early 1980s to contemporary observations by filming the same public space from similar angles. He is convinced that mobile device users provide a number of benefits to the social life of spaces, people are actually more likely to spend time in groups and there has been increase of women. Even if people are alone checking the news, reading blogs, or talking on the phone, still they are part of public space. He is convinced that design that takes technology into consideration is paramount for the future of cities.

MediaTeam Oulu (Ylipulli et al. 2013) has studied the appropriation process of two public computing infrastructures in the City of Oulu, Finland, a municipal WiFi network (pan OULU WLAN) and large interactive displays, which should provide novel applications and services to people. Some services enable the pairing of the mobile phone with the display by using Bluetooth, QR codes, and SMS. Municipal WiFi has been adopted very well and its usage is increasing rapidly. The adoption of the interactive public displays has been slow due to unfamiliarity of the technology and its questionable utility. Different demographic groups may experience these factors in differing ways; for example, for young people the creativity and playfulness of the applications was a more attractive feature than for elderly.

As the use of digital networks becomes an essential part of everyday life, a new digital layer is added on the existing urban landscape (Markaki 2014). This information age and the revolution have influenced the way people interact with each other and with their surrounded physical space. Information and communication are two essential factors of interest and attraction specific to urban environments and at the same time they represent key factors for the progress of the city, as bringing people together and supporting exchange of ideas generate development. Technology is only $10 \%$ of the problem. Ninety percent of it is about how it is used to connect and for a better quality of life. Technology is making it easier for people to connect to the places that they inhabit. The creation of hotspots providing wireless Internet access encouraged the return to the public, for both work and recreation. In addition, social media has a high potential for encouraging social interaction, in virtual as well as in real life public spaces, thus connecting them. The use of ICTs can significantly enhance public space, 
by creating access points to information and supporting education. In this sense, augmented reality can complete the toolbox, playing a significant role in engaging users and personalizing the urban experience.

The development of ICTs tools and the mobility of modern devices also bring new demands regarding urban design and the way public spaces are being planned. Namely, public spaces have to provide resources for proper functioning of gadgets (e.g., electricity, plugs). Street furniture should be able to satisfy the users' needs through its usage, comfort, quantity, accessibility, arrangement and aesthetics. They should be secured to avoid collapse by natural or human forces, and they should be regularly maintained by cleaning and repairing them. They have also to be easily adjustable in order to accommodate different activities, and have to encourage the shift of more and more activities from indoors to outdoors. Apart from the physical infrastructure, in order to successfully integrate ICTs in the urban life, the community has to be trained and prepared to embrace the change.

\section{Blended Spaces - Spaces and Places for Human Interaction and Experiences}

Human-Computer Interaction (HCI) is traditionally dealing with the design, evaluation and implementation of interactive computing systems for human use and the study of phenomena related to humans involved in these phenomena. As such, HCI has a more narrow approach than for example Interaction Design (ID). Interaction Design is concerned with the theory, research and practice of designing user experiences for all types of technologies, systems, objects and products. The process of interaction design involves basically four activities (Preece et al. 2011): Establishing requirements; Designing alternatives; Prototyping and Evaluation (ibid, 15). A similar, more recent approach has been mentioned as the Human-Centered Informatics (with the same abbreviation HCI). Human-Centered Informatics approach deals with the intersection of the cultural, the social, the cognitive, and the aesthetic with computing and information technology. Generally, Human-Centered Informatics deals with a more challenging area that includes the goals and activities of people, their values, and the tools and environments that help shape their everyday lives (Bannon 2011). HCI and Interaction Design (ID) are changing our ways of interacting and experiencing services and objects within our daily life and in our professional life as well. This involved designing for interaction on a broad macro-level as in our environmental surroundings to interaction on a micro-level. Today, when deigning, interaction is considered as a main component of the design process. Besides the focus on interaction design and $\mathrm{HCI}$ issues, user experience (UX) is also getting more and more attention and across different populations, devices and places/spaces. Thus, this means that we are moving around in different spaces and places inhabited with both physical objects and surroundings as well as interacting with digital objects and services. These spaces can be viewed as blended spaces (Benyon 2012). Furthermore, they are to be recognised as extended, but also as new social and cultural spaces. Finally, these blended spaces also constitute extended conceptual spaces. 
User experience (UX) concerns the navigation of and within different spaces and how people experience this. Moving in and through the spaces and understanding spaces is an important human activity. Navigation is concerned with finding out about an environment. Three important activities are included (Benyon and Höök 1997):

- Object identification, (understanding and classifying the objects in an environment).

- Exploration, (exploring a local environment and how that environment relates to other environments).

- Wayfinding, (navigating toward a known destination).

\section{Conclusions}

Blended spaces applied in landscape design have close connection to user's experiences. As such, they can also constitute an environmental space and place that will affect humans and human activity (Parviainen, Lagerström and Hansen 2017). Design on a general level is very much about crafting your surroundings and often draws upon engineering, material and creative approaches. As Benyon (2014: 21) points out, design has been described by Donald Schön as a "conversation with materials". Schön means that in any type of design, designers must understand the nature of the materials that they are working with (Schön 1983). Thus, in landscape, environmental and urban design, knowledge and skills about both digital and physical material (Wang et al. 2017a, 2017b) is important since they surround us in our daily and everyday life. Blended spaces are spaces, or environments, where a physical space is explicitly integrated into a digital space. Blended spaces are conceptually close to tangible interactions (Wang et al. 2017a, 2017b) where the physical and digital are integrated. The purpose and understanding of designing a blended space are to enable people and groups of people to feel present in place, interacting with content and objects through senses and activities of the blended space (Benyon 2014).

Some challenges when designing for interaction are that designers need to think and elaborate beyond the immediate use of a place/space and consider wider physical, digital, cultural and social settings. Additional issues that are important is how interactions change over time and locations, as well as how content is experienced through different physical and digital objects and devices. People collaborating within physical and digital spaces and how information is created, shared and searched for is important (Hansen and Järvelin 2005). A further challenge is to deal with the human. People are flexible, dynamic, traditional, creative and resourceful. However, physical and digital 'systems' tend to be stable, static, with predefined goals, tasks and processes. This creates a challenge and a barrier that need to be focused on and dealt with. Since people's behaviour, language, feelings etc., that need to be recognized when designing for these spaces and places. As Benyon (2014: 22) points out, designers need to create and establish interfaces and systems that "enable people to shape and achieve their goals and aspirations. These interfaces should include and inherit different physical, digital, perceptual, sensory and conceptual point of contact that are between people and the content that is contained and accessible by. 


\section{References}

Chua, A., Servillo, L., Marcheggiani, E., Moere, A.V.: Mapping cilento: using geotagged social media data to characterize tourist flows in Southern Italy. Tour. Manag. 57, 295-310 (2016)

Abdel-Aziz, A.A., Abdel-Salam, H., El-Sayad, Z.: The role of ICTs in creating the new social public place of the digital era. Alex. Eng. J. 55, 487-493 (2016)

Chua, A., Marcheggiani, E., Servillo, L., Vande Moere, A.: FlowSampler: visual analysis of urban flows in geolocated social media data. In: Aiello, L.M., McFarland, D. (eds.) SocInfo 2014. LNCS, vol. 8852, pp. 5-17. Springer, Cham (2015). https://doi.org/10.1007/978-3-31915168-7_2

Bannon, L.: Reimagining HCI: toward a more human-centered perspective. Intersections 18(4), 50-57 (2011)

Benyon, D., Höök, K.: Navigation in information spaces: supporting the individual. In: Proceedings of the Human-Computer Interaction INTERACT 1997, pp. 39-46 (1997)

Benyon, D.: Presence in blended spaces. J. Interact. Comput. 24, 219-226 (2012)

Benyon, D.: Spaces of interaction, places for experience. Synthesis Lectures on Human-Centered Informatics, September 2014. https://doi.org/10.2200/s00595ed1v01y201409hci022)

Carmona, M.: Public Places, Urban Spaces. Architectural Press, Oxford (2003)

Carr, S.: Public space. Cambrige University Press, Cambrige (1992)

Castells, M., Fernández-Ardèvol, M., Linchuan Qiu, J., Sey, A.: Mobile Communication and Society: A Global Perspective. MIT Press, Cambridge (2006)

Francis, M.: Mapping downtown activity. J. Arch. Plan. Res. 1(1), 21-35 (1984). http://lda. ucdavis.edu/people/websites/francis/Mapping\%20Downtown\%20Activity-Francis.pdf

Galli, A., Di Clemente, M.V., Marcheggiani, E., Scoppolini, F.M.: The design of ICT tools to strengthen the local identity in rural areas and to broaden the participation of large public to rural tourism experiences. In: The European Pilgrimage Routes for Promoting Sustainable and Quality Tourism in Rural Areas International Conference, 4-6 December 2014, Florence Italy, Proceeding, pp. 871-880 (2015)

Gehl, J.: Life between Buildings: Using Public Space. Island Press, Washington, DC (2011)

Hampton, K.N.: Technology Brings People Together in Public Spaces After All, published on line By Project for Public Spaces on 17 July 2014 (2014)

Hansen, P., Järvelin, K.: Collaborative information retrieval in an information-intensive domain. Inf. Process. Manag. 41(5), 1101-1119 (2005)

Lipovská, B., Štěpánková, R.: Assessing observation methods for landscape planning practice in rural villages. Curr. Urban Stud. 1, 102-109 (2013). https://doi.org/10.4236/cus.2013.14011

Lugano, G.: Mobile social networking in theory and practice. First Monday, 13(11), 3, November 2008. http://firstmonday.org/ojs/index.php/fm/article/view/2232/2050

Lynch, K.: Site Planning. MIT Press, Cambridge (1984)

Madanipour, A.: Design of Urban Space. Wiley, Chichester (1996)

Markaki, M.: Digital Cities: Towards a New Identity of Public Space. London (2014)

Miková, P.: Manuál tvorby veřejných prostranství hlavního města Prahy. Institut plánování a rozvoje hlavního města Prahy, 290 p. (2014). ISBN 978-80-87931-11-0

Miková, K., Paulíková, M., Pauliniova, Z.: Verejné priestory - ako tvorit' priestory s príbehom, pre l'udí a s l'ud'mi. EKOPOLIS: Banská Bystrica, 2010, 135 p. (2010). ISBN 978-80-89505$00-5$

Nassar, U.A.: Urban space design to enhance physical activities and motivate healthy social behaviour in Caro, Egypt. In: Proceedings of INTCESS15-2nd, International Conference on Education and Social Sciences, pp. 1137-1147 (2015) 
Parviainen, E., Lagerström, E., Hansen, P.: Composting as interior design - encouraging sustainability throughout a participatory design process. In: DIS 2017 Companion Proceedings of the 2017 ACM Conference Companion Publication on Designing Interactive Systems, June 2017, Edinburgh, UK, pp. 167-171 (2017). https://doi.org/10.1145/3064857.3079139

Preece, J., Sharp, H., Rogers, Y.: Interaction Design: Beyond Human-Computer Interaction, 3rd edn. Wiley, Chichester (2011)

Project for Public Space (PPS): How to turn a Place Around: A Handbook for Creating Successful Public Spaces. Project for public spaces, New York (2001)

Schöbel, S.: Qualitative research as a perspective for urban open space planning. J. Landsc. Arch. 1(1), 38-47 (2006)

Schön D.A.: The Reflective Practitioner. Basic Books. 2 Place; Publisher? (1983)

Thwaites, K., Simkins, I.: Experiential landscape: an approach to people, place, and space. Milton Park, Abingdon, New York (2007)

Ingegnoli, V.: Landscape Bionomics Biological-Integrated Landscape Ecology. Springer, Milano (2015). https://doi.org/10.1007/978-88-470-5226-0

Vanderhaeghen, P., Cheng, H.J.: Guidance molecules in axon pruning and cell death. Cold Spring Harb. Perspect. Biol. 2(6), 1-18 (2010)

Wang, Y., Luo, S., Liu, S., Lu, Y., Hansen, P.: Crafting concrete as a material for enhancing meaningful interactions. In: Kurosu, M. (ed.) HCI 2017, Part I. LNCS, vol. 10271, pp. 634644. Springer, Cham (2017). https://doi.org/10.1007/978-3-319-58071-5_48

Wang, Y., Lou, S., Lu, Y., Gong, H., Zhou, Y., Liu, S., Hansen, P.: AnimSkin: fabricating epidermis with interactive, functional and aesthetic color animation, June, 2017, Edinburgh, UK (2017b). http://dx.doi.org/10.1145/3064663.3064687

Wheeler, S.: The sustainable urban development reader. Routledge, London (2004)

Whyte, W.H.: The Social Life of Small Urban Spaces, The Conservation Foundation. Washington DC (1980)

Ylipulli, J., Suopajärvi, T., Ojala, T., Kostakos, V., Kukka, H.: Municipal WiFi and interactive displays: Appropriation of new technologies in public urban spaces. Technol. Forecast. Soc. Chang. 89(2014), 145-160 (2013)

Žufová, M.: Lepšie data pre lepšiu Bratislavu. In: Public Spaces Bratislava. STU Bratislava, 28 p. (2015). ISBN: 978-80-227-4355-6

Open Access This chapter is licensed under the terms of the Creative Commons Attribution 4.0 International License (http://creativecommons.org/licenses/by/4.0/), which permits use, sharing, adaptation, distribution and reproduction in any medium or format, as long as you give appropriate credit to the original author(s) and the source, provide a link to the Creative Commons license and indicate if changes were made.

The images or other third party material in this chapter are included in the chapter's Creative Commons license, unless indicated otherwise in a credit line to the material. If material is not included in the chapter's Creative Commons license and your intended use is not permitted by statutory regulation or exceeds the permitted use, you will need to obtain permission directly from the copyright holder.

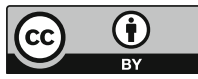

